DOI: $10.25100 /$ pfilosofica.v0i53.11520

\title{
RETRATOS DE SPINOZA
}

\section{Jean-Paul Margot}

Universidad del Valle, Cali, Colombia

\section{Resumen}

Hay muchos retratos de Spinoza, pero ninguno de ellos está bien documentado, al menos suficientemente documentado como para satisfacer las exigencias del método iconográfico. Por falta de argumentos objetivos que permitan identificar a Spinoza entre tantos cuadros y grabados, tal vez podamos considerar que el "verdadero" retrato de Spinoza es el frontispicio de las Opera posthuma de 1677.

Palabras clave: grabado; iconografia; pintura; retrato; teatro.

Cómo citar este artículo: Margot, J-P. (2021). Retratos de Spinoza. Praxis Filosófica, (53), 85-108. https://doi.org/10.25100/pfilosofica.v0i53.11520

Recibido:16 de febrero de 2021. Aprobado: 24 de abril de 2021. 


\title{
Portraits of Spinoza
}

\author{
Jean-Paul Margot ${ }^{1}$ \\ Universidad del Valle, Cali, Colombia
}

\begin{abstract}
Although there are many portraits of Spinoza, none is well documented, or at least sufficiently documented to satisfy the requirements of the iconographic method. Due to the lack of objective arguments that could allow us to identify Spinoza among so many paintings and etchings, we might perhaps consider that the "real" portrait of Spinoza is found on the frontispiece of 1677's Opera posthuma.
\end{abstract}

Keywords: Etching; Iconography; Painting; Portrait; Theater.

${ }^{1}$ Profesor jubilado del Departamento de Filosofía de la Universidad del Valle. Se doctoró en la Universidad de Ottawa, Canadá, con la tesis: "Razón y ficción en Descartes". Publicó, con Lelio Fernández, una traducción, con estudio preliminar, notas y comentarios, del Tratado de la reforma del entendimiento y otros escritos de Baruch Spinoza, Madrid, Tecnos, 1989, (2003). Pertenece al grupo de investigación Ágora, diálogo entre antiguos y modernos, del Departamento de Filosofía de la Universidad del Valle. E-mail: jpaulmargot@gmail.com 


\section{Portraits de Spinoza}

\section{Résumé}

Il y a beaucoup de portraits de Spinoza, mais aucun n'est bien documenté, au moins suffisamment documenté pour satisfaire les exigences de la méthode

iconographique. À défaut d'arguments objectifs qui permettent d'identifier Spinoza parmi tant de peintures et de gravures, peut-être est-il possible de considérer que le "vrai" portrait de Spinoza est le frontispice des Opera posthuma de 1677.

Mots-clés: gravure; iconographie; peinture; portrait; théâtre. 


\title{
RETRATOS DE SPINOZA
}

\author{
Jean-Paul Margot \\ Universidad del Valle, Cali, Colombia
}

No es de extrañar que un filósofo que situaba siempre al ser humano en el contexto general de la naturaleza, no sintiera la necesidad de hacer su retrato. Por eso parece muy probable que no tengamos ningún retrato auténtico de Spinoza (Belinfante, Kingma \& Offenberg, 1977, p. 12).

¿Qué aspecto tenía Spinoza? ¿Cómo se veía Spinoza? Tan sólo una fotografía, con la información de quién la tomó, dónde y cuándo, nos permitiría saberlo ${ }^{2}$. Varios retratos han sobrevivido, pero ninguno de ellos está bien documentado, al menos suficientemente documentado como para satisfacer las exigencias del método iconográfico. Los elementos de las imágenes de Spinoza, los elementos ilustrados, tienen un significado iconográfico siempre y cuando estén relacionados con su filosofía. Ahora, al no tener una prueba de la relación entre la imagen y los textos, excedemos fácilmente los límites de la iconografía, y nos adentramos en el campo de la especulación. Debemos, entonces, evitar el escollo del método iconográfico, que termina, a veces, sustituyendo a la obra su texto-fuente ${ }^{3}$, y los riesgos de la sobreinterpretación, a menudo asociada con la iconología ${ }^{4}$. En otros

2"Los fotógrafos tocan lo real y lo reproducen. Pero su producto, a pesar de ser verdadero, o justamente por eso mismo, no es bello. Con la pintura sucede lo contrario. Todo en ella es aproximación, sugerencia, insinuación. La pintura representa, estimado Madeleine. Pero en esa representación los espectadores rozamos la belleza porque no vemos sino que imaginamos" (Montoya, 2019, p. 26).

3 "He escrito sobre iconografía y, de hecho, esto me gusta mucho. Además he hecho contribuciones que creo sólidas: sobre El Bosco, sobre Giulio Romano o sobre Poussin, donde espero haber resuelto verdaderamente el problema. Puedo decir: tal pintura proviene de tal texto" (Gombrich 1993, 169).

${ }^{4}$ Véase a E. Panofsky: El capítulo I de Meaning in the visual Arts: "Iconography and Iconology: an Introduction to the study of Renaissance Art", cuya primera edición es de 1955, reproduce casi textualmente la Introducción de Studies in Iconology publicado en 1939, en Nueva York (Panofsky, 1955, pp. 26-54; 1972, 3-32). Como bien lo señala R. van Straten en su Una introducción a la iconografia: "En la práctica no se puede combinar la iconografía ("descripción de la imagen") y la iconología ("explicación de la imagen”)" (Van Straten, 2000, p. 18). "Dividir la tercera fase de Panofsky en dos fases separadas nos permite, en mi opinión, definir los términos iconografía e iconología con un poco más de precisión:

1)La iconografía es la rama de la disciplina de la Historia del Arte que se ocupa del tema (subject matter) en el arte, y de su significado o contenido más profundo (como lo pretende el artista), y 2) La iconología es aquella rama de la disciplina de la Historia Cultural que 
términos, hay que conservar una prudente distancia entre la obra de arte y el texto que debería comentarla y explicarla.

Hay poco espacio para la prudencia en lo que llamaremos "la controversia Vecht". Hojeando el catálogo de octubre de 2013 de la casa de subastas Ader Norman en Paris, Constant Vecht, comerciante de arte y director de la galería Kunstzalen A. Vecht, en Ámsterdam, se encontró con una pintura titulada "Retrato de un hombre frente a una escultura", atribuida a Barend Graat (1628-1709)5 , un pintor holandés menor del siglo XVII. Vecht inmediatamente identificó al modelo como Spinoza, y compró el cuadro por 3000 euros (Wecker, 2016).

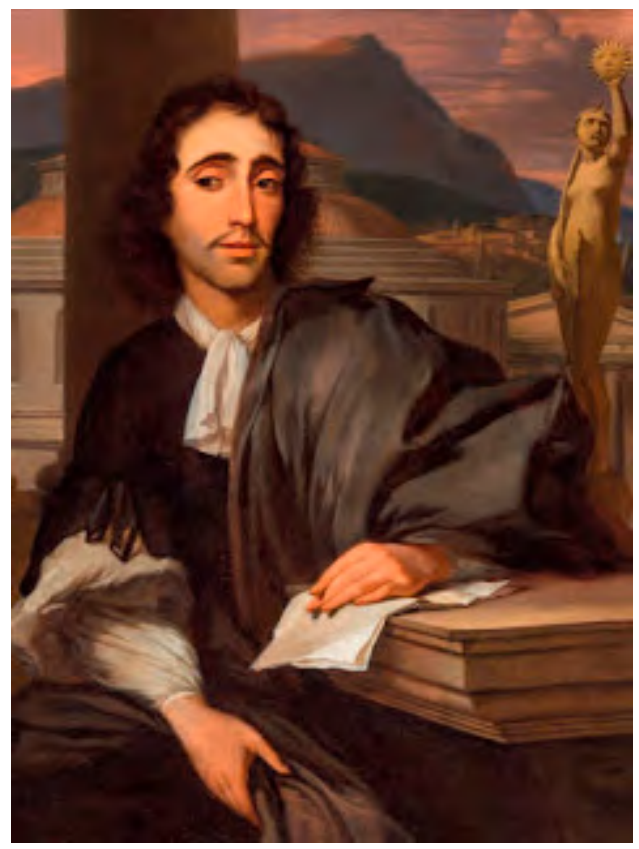

Retrato de un hombre, óleo sobre tela de 47 x $40 \mathrm{cms}$. Wikimedia Commons. Dominio público.

tiene como tarea descubrir el trasfondo cultural, social e histórico de los temas (subjects) en el arte, y explicar a partir de este trasfondo por qué un determinado tema (subject) fue elegido por cierta persona (artista o comitente) en un determinado lugar y en un determinado momento (período), y por qué el tema (subject) está representado de una forma determinada (Van Straten, 1986, p. 170).

${ }^{5}$ En la parte inferior izquierda del cuadro está la firma "BGF 1666", es decir, "Barend Graat fecit (hecho por Barend Graat)", en 1666. 
Desde 2015 historiadores del arte y restauradores de arte han participado en un debate acerca de la autenticidad del cuadro y del parecido del retrato con Spinoza ${ }^{6}$. En marzo de 2016 Vecht llevó el cuadro a la Feria europea de Bellas Artes en la ciudad holandesa de Maastricht, donde le colocó el precio de \$ 2.5 millones. Pero varios años después, la pintura todavía está en el inventario de su dueño. Parece que su identificación todavía tiene muchos escépticos.

Hay muchos retratos de Spinoza, pero ninguno fiable. Retratos que expresan sólo impresiones subjetivas, como las descripciones verbales que el fraile agustino Tomás Solano y Robles y el capitán Miguel Pérez de Maltranilla, que conocieron a Spinoza en Ámsterdam en 1658, dieron de él a la Inquisición española en 1659.

A finales de 1656 cumplió Spinoza veinticuatro años. Según las descripciones que el Hermano Tomás y el Capitán Maltranilla dieron de él tres años más tarde, Spinoza era un joven bien parecido, con una inconfundible apariencia mediterránea. El fraile lo describe como "un hombre de pequeña estatura, con un bello rostro, de tez pálida y de cabellos y ojos negros". El capitán añade que "su cuerpo era delgado y bien formado, sus cabellos largos y negros, y su cara bella, adornada con un pequeño bigote también negro". El filósofo alemán Gottfried Wilhelm Leibniz, que visitó a Spinoza en 1676, lo describió como "un hombre pálido de color, y un aire español en su rostro". Los presuntos retratos de Spinoza de aquel período [...], muestran un rostro alargado y delgado, sin barba, y cuyo color confirman todos estos informes"; "Ninguno de estos retratos ha sido autenticado, sin embargo, como una representación de Spinoza (Nadler, 1999, pp. 155; 370).

Desde luego, un verdadero retrato de Spinoza como el "Retrato de un hombre frente a una escultura" sería interesante, pero no revelaría mucho más de lo que parecía el filósofo ${ }^{7}$. Además, es muy poco probable que Spinoza haya posado para un retrato o que lo haya encargado. Como bien lo dice J. Kingma, "No es de extrañar que un filósofo que situaba siempre al ser humano en el contexto general de la naturaleza, no sintiera la necesidad de que le hicieran su retrato. Por eso parece muy probable que no poseamos

6 "Después de encargar a los dos institutos forenses más grandes de Holanda que compararan el retrato con representaciones póstumas conocidas de Spinoza, Vecht concluyó que tenía en mano la única representación conocida del filósofo creada durante la vida de Spinoza. Cada detalle de los labios, las cejas y los ojos extravagantes coincidían" (Wecker, 2016).

7 "Los iconógrafos de retratos han aprendido por experiencia que una supuesta semejanza es una de las peores guías para identificar a los sujetos de los retratos, y la semejanza sólo es un argumento válido si se combina con otros argumentos más objetivos” (Ekkart, 1999, p. 26). 
ningún retrato auténtico de Spinoza" (Belinfante, Kingma \& Offenberg, 1977, p. 12). Asumiendo que el "Retrato de un hombre frente a una escultura" es, en efecto, de Barend Graat, su procedencia truncada, el hecho de que "aparece en Francia en 1982 sin rastros anteriores en los registros históricos", no deja de preocupar (Schliesser, 2016b). La principal causa de escepticismo es el fondo del cuadro, que incluye una arquitectura romana, una pirámide y una escultura. La arquitectura podría simbolizar la confianza de Spinoza en la filosofía romana ${ }^{8}$, pero la aparición del Panteón, un símbolo del poder imperial, es una elección extraña. La escultura es una mujer desnuda parada en un globo que tiene un sol en su mano izquierda y una palma en su mano derecha, dos imágenes que son difíciles de relacionar con algún tema spinociano. Si bien la escultura puede simbolizar "la verdad", lo que podría sugerir que se trata del retrato de un filósofo, "estamos muy lejos de la luz interior que Descartes y Spinoza preferían" (Schliesser, 2016a). En síntesis, las imágenes paganas del fondo del cuadro no son consistentes con los escritos de Spinoza; revelan un excesivo gusto por la imaginación, un género de conocimiento que Spinoza define así en la Ética:

Por todo lo anteriormente dicho resulta claro que percibimos muchas cosas y formamos nociones universales: $10^{\circ}$ ) a partir de cosas singulares que nos son representadas por los sentidos de forma mutilada, confusa y sin orden al entendimiento (ver $2 / 29 \mathrm{c}$ ); y por eso he solido calificar tales percepciones de conocimiento por experiencia vaga. $2 .^{\circ}$ ) A partir de signos, como, por ejemplo, que al oír o leer ciertas palabras, recordamos las cosas $\mathrm{y}$ formamos de ellas algunas ideas semejantes a aquellas con que solemos imaginarlas (ver 2/18e). A estos dos modos de contemplar las cosas los llamaré en adelante conocimiento de primer género, opinión o imaginación $(\mathrm{E} 2 \mathrm{P} 40 \mathrm{~S} 2)^{9}$

${ }^{8}$ El inventario de la biblioteca que Spinoza dejó después de su muerte revela que poseía numerosas obras de autores latinos -al igual que una edición en griego de la Ilíada y de la Odisea de Homero-: Tácito, T. Livio. Virgilio, Salustio, Ovidio, Epicteto y Séneca, entre otros -Véase a Spinoza, 1995, pp. 200-220-, lo que es, probablemente, una consecuencia de la enseñanza impartida por F. van den Lenden (1602-1674) en la escuela "latina" que fundó en 1652, y que atendió Spinoza; véase infra, nota 24.

${ }^{9}$ Acerca de este primer género de conocimiento, o modo de percibir, véase, también, Tratado de la reforma del entendimiento (Spinoza, 2007, par. 19) -Percepción por el oído o por algún signo-, y Tratado breve (Spinoza, 1990, II, cap. 1 y 2)-Creencia sola u opinión: por oído-decir, por experiencia-. El conocimiento imaginativo es un conocimiento centrado en el cuerpo propio: "a las afecciones del cuerpo humano, cuyas ideas nos representan los cuerpos exteriores como presentes, las llamaremos imágenes de las cosas, aunque no reproducen las figuras de las cosas; y cuando el alma contempla desde esta perspectiva los cuerpos, diremos que los imagina" (E2P17S2). 
Un conocimiento a partir de signos es también un conocimiento imaginativo, porque la relación del signo con la cosa significada está basada, según Spinoza, en la asociación de ideas, es decir, en una operación de la imaginación. Conforme con el Apéndice de la Primera parte de la Ética, Spinoza le escribe a H. Oldenbrg en su la carta del 20 de noviembre de 1665: "yo no atribuyo a la naturaleza belleza ni deformidad, orden ni confusión. Porque las cosas no se pueden llamar hermosas o deformes, ordenadas o confusas, sino respecto a nuestra imaginación" (Spinoza 1988, pp. 235-236).

Tampoco hay mucho espacio para la prudencia en la identificación de Spinoza en dos cuadros de Rembrandt y en uno de Vermeer. El hecho de que Rembrandt viviera durante varios años en el barrio judío de Ámsterdam, en la Breestraat, cerca de la casa donde nació Spinoza ${ }^{10}$, su relación con Menasseh ben Israel, del que hizo un retrato pintado y un grabado, su interés artístico por los judíos sefardíes, a quienes dibujó, pintó y grabó profusamente, al igual que sus numerosos óleos sobre el Antiguo Testamento ${ }^{11}$, alimentan la fábula en la que se reconoce a Spinoza bajo los rasgos del arpista arrodillado ante el rey en la pintura de Rembrandt David tocando el arpa para Saúl.

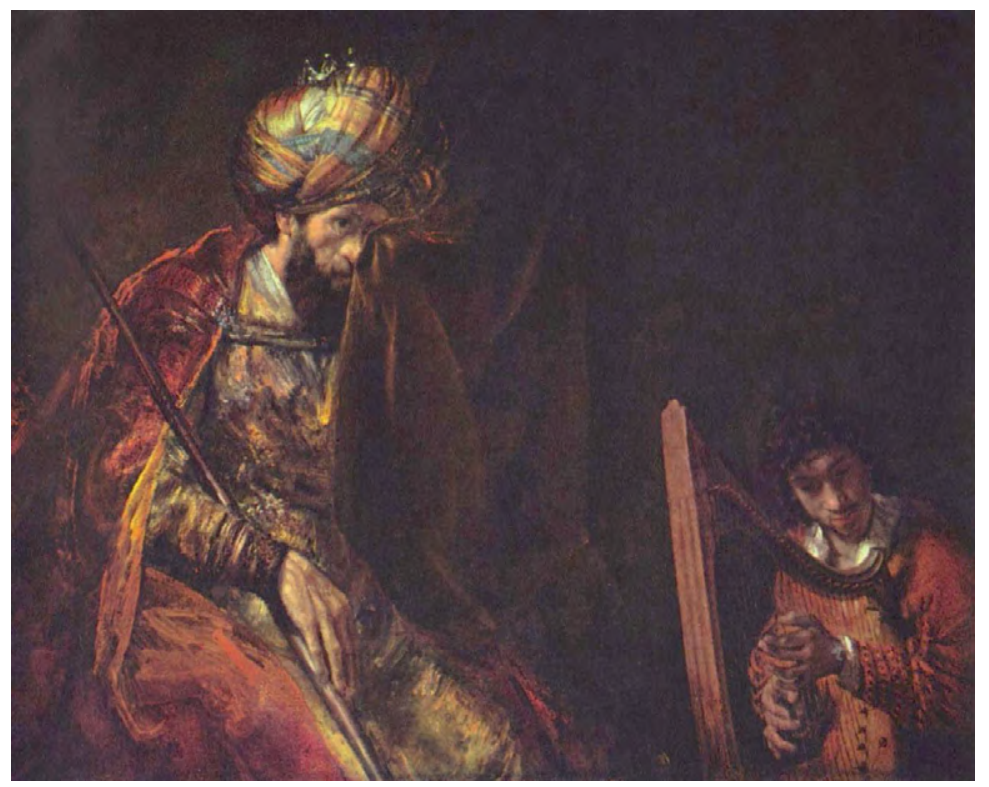

Rembrandt, Saúl y David, Mauritshuis, La Haya, Holanda. Wikimedia Commons. Dominio público.

${ }^{10}$ Si bien es posible que Spinoza y Rembrandt se hayan conocido, no hay ninguna evidencia que lo compruebe: véase a (Nadler, 1999, pp. 78-79).

${ }^{11}$ Véase a (Nadler, 2003), passim. 
Óleo sobre lienzo, de 130,5 cms x $164 \mathrm{cms}$, posiblemente pintado entre 1650 y 1655, "Saúl y David" pertenece a la serie de temas bíblicos. Cuenta la historia de Saúl y David (1 Samuel 16: 14-23). Saúl está atormentado por "un espíritu malo de parte de Jehová", y uno de sus criados le recomienda buscar a David "que sabe tocar, y es valiente y vigoroso y hombre de guerra, prudente en sus palabras y hermoso, y Jehová está con él" (1 Samuel 16: 18) para aliviarlo. La imagen representa el momento en que David toca la música con su instrumento, y el Rey Saúl escucha atentamente -"Y cuando el espíritu malo de parte de Dios venía sobre Saúl, David tomaba el arpa y tocaba con su mano; y Saúl tenía alivio y se sentía mejor, y el espíritu malo se apartaba de él" (1 Samuel 16: 23)-. La figura del rey, vestido con ropas orientales, ocupa la mayor parte del cuadro, lo que indica su importancia y significado. La de David, abajo a la derecha, no es tan significativa, pero algunos ven en los rasgos de este peculiar David que humaniza al rey el tipo de los judíos portugueses que poblaban el barrio Vlooienburg, en Ámsterdam ${ }^{12}$. Por sugestiva que pueda resultar, la idea de que Rembrandt retratara a Spinoza en este papel no deja de ser una fantasía de la biografía novelística moderna ${ }^{13}$. Otro tanto sucede con El geógrafo de Vermeer (1669), óleo sobre lienzo, de $53 \mathrm{cms}$ x 46,6 cms, pintura de representante de una ciencia de la naturaleza muy cultivada en los Países Bajos, que hace juego con el El astrónomo (1668).

${ }^{12}$ Otro retrato de Rembrandt ha sido identificado como el de Spinoza: "Otro investigador ha afirmado haber descubierto el rostro de Baruch Spinoza en el cuadro "Hombre con lupa", ahora en el Museo Metropolitano de Nueva York. Como es bien sabido, Spinoza se ganaba la vida puliendo lentes. Este retrato tiene, sin embargo, una pieza que lo acompaña, que representa a una mujer sosteniendo un clavel en su mano, lo que indica que la supuesta imagen de Spinoza es la de un hombre casado, mientras que Spinoza permaneció soltero toda su vida. Esta suposición, por lo tanto, también carece de fundamento, además del hecho de que los rasgos del hombre de este cuadro no tienen ningún parecido con los retratos bien autentificados de Spinoza. Sólo recientemente se ha afirmado, sobre mejores bases, que es el retrato del platero holandés Jan Lutma, el joven" (Landsberger, 1962, pp. 53-54). Basándose en el hecho de que "Man with a magnifying glass" forma "pendant" con "Woman with a pink Carnation (Mujer con un clavel rosado)", (Ekkart, 1999, pp. 26-27) desestima también esta identificación. El cuadro podría ser el retrato del subastador Pieter Haringh (1609-1685).

${ }^{13}$ Un buen ejemplo es el artículo de (Coffier, 1916). 


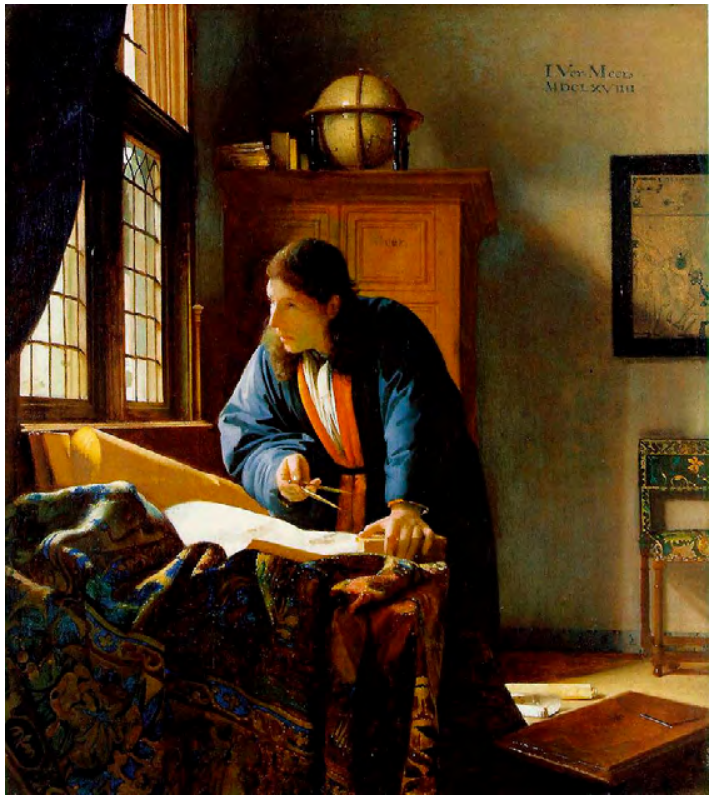

Johannes Vermeer, El geógrafo, Städel Museum, Fráncfort del Meno, Alemania. Wikimedia Commons. Dominio público.

Vestido con una bata de tejido azul en un rico decorado, una mano apoyada en un libro sobre una mesa llena de mapas y papeles, la otra sosteniendo un compás, ligeramente inclinado hacia adelante, levanta los ojos y mira pensativo a lo lejos por una ventana; encima del armario hay un globo terrestre al lado de unos libros. Según la tradición, el rostro sin barba de largos cabellos sería el de Spinoza, pero ninguna evidencia confirma esta identificación.

Hay muchos retratos de Spinoza, pero ninguno fiable. Colerus, uno de sus biógrafos, y pastor de la iglesia luterana, hace de él una descripción verbal que nada tiene que ver con la iconografía del geógrafo:

Respecto a su persona y fisionomía, es aquí bastante conocida y aún viven muchos que han tratado frecuentemente con él. Era de estatura media y de facciones bien proporcionadas. Por su fisionomía podía fácilmente adivinarse que procedía de judíos portugueses, ya que su tez era bastante morena, su cabello rizado y negro, y sus cejas largas y negras. Su forma de vestir era sencilla y corriente, sin que le importara mucho cómo iba vestido. Como en casa solía llevar una bata raída, en una ocasión se le echó en cara un consejero distinguido. Pero él le replicó: «¡es que entonces voy a ser 
yo otro hombre? Mala cosa es que el saco sea mejor que la carne que va dentro» (Spinoza, 1995, p. 112) ${ }^{14}$.

Sabemos, de nuevo por Colerus, que Spinoza dibujaba ${ }^{15}$. En el cuaderno donde estaban reunidos sus dibujos había un hombre en camisa, con una red de pescador al hombro y el sombrero de los amotinados napolitanos durante la revuelta de 1647, la mirada triste, y un mapa de Sicilia al fondo.

Aprendió por sí mismo la pintura, hasta poder dibujar a tinta o carbón a cualquiera. Tengo en mis manos todo un librito con esos dibujos, en los que ha retratado a distintos personajes relevantes que le eran conocidos y que ocasionalmente le habían visitado. Entre éstos encuentro en la página cuatro un pescador dibujado en mangas de camisa y con una red de barco sobre el hombro derecho, justamente de la forma en que los grabados históricos han dibujado al célebre jefe rebelde de los napolitanos, Masaniello (Spinoza, 1995, p. 110).

${ }^{14}$ ¿Será que Gebhardt pensaba en esta descripción de la tez y del cabello de Spinoza cuando escribía: "A la moda barroca obedecía su cabello, que caía sobre los hombros en negras volutas, marco del oliváceo rostro" (Gebhardt, 1929, p. 320)? Sobre "el espinocismo como expresión del barroco", véase también a (Gebhardt, 1977, pp. 94-97).

${ }^{15}$ Véase a J. Berger, Bento's sketchbook (Berger, 2011) 


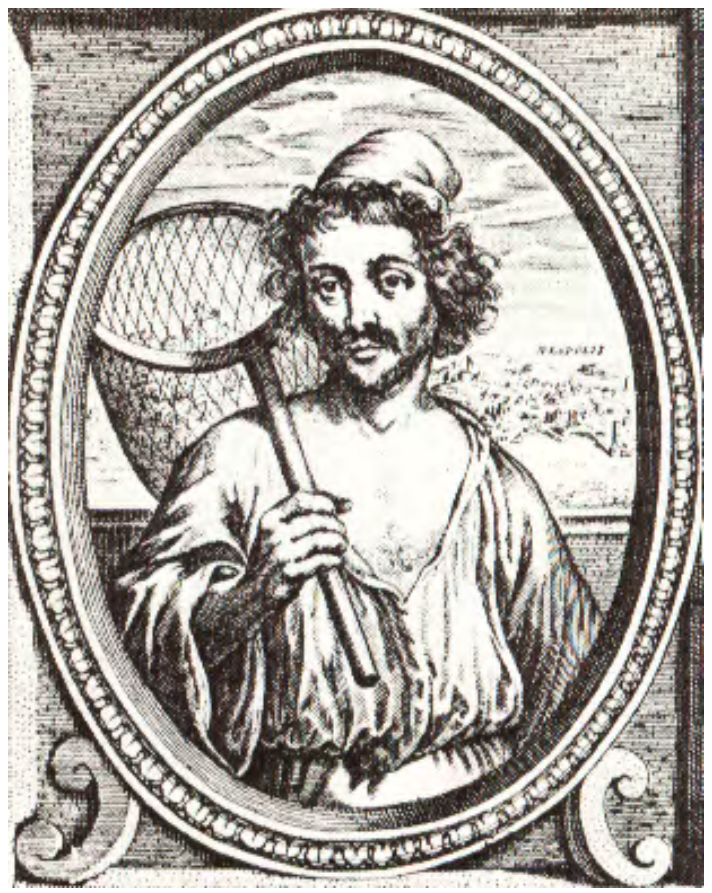

"Masaniello" de Pieter de Jode (ca. 1660), Rijksmuseum, Ámsterdam. Wikimedia Commons. Dominio público.

Se ha hablado de autorretrato: "A este respecto, relata Colerus, me decía el señor Hendryck van der Spyck, que fue el último hospedero de Spinoza, que éste se parecía a él punto por punto y que seguramente lo había esbozado sobre su propio rostro" (Spinoza, 1995, p. 110) ${ }^{16}$.

Lo que empieza como una protesta de los habitantes de Nápoles, entre el 7 y el 16 de julio de 1647 -cuando la misma multitud que aclamó a Massianello lo asesinó, le cortó la cabeza y se la llevó al virrey-contra la

${ }^{16}$ En su Spinoza im portrait The unknown face, R. Ekkart desestima "la miniatura a menudo reproducida por Hendrick van der Spijck en los Archivos Reales de La Haya [...] La ropa usada por el sujeto sugiere que la pintura se hizo alrededor o justo después de 1670, pero es demasiado joven para ser Spinoza" (1999, 27). Inicialmente rotulada como el "Retrato de un sujeto desconocido por un artista holandés desconocido", la miniatura fue posteriormente relacionada, sin mucha argumentación, con el pintor ornamental y casero de Spinoza en La Haya (Ibid. 9). Kingma piensa lo mismo (Belinfante, Kingma \& Offenberg, 1977, p. 13, fig. 5). Spinoza se traslada a la casa de Van der Spijck, en La Haya, en 1670, "un pintor que podía haber despertado el interés de Spinoza por el dibujo durante los últimos años de su vida en La Haya" (Totaro, 2020, 30). En abril de 1663, Spinoza se había trasladado a Voorburg, en las afueras de La Haya, e instalado en la casa de otro pintor, D. Tydeman: véase a (Nadler, 1999, pp. 203-204). 
carestía de los alimentos, el mal gobierno y la alta presión fiscal debida a las necesidades bélicas, se convierte rápidamente en una revuelta antifeudal y antiespañola de las poblaciones de las provincias. La sublevación que lidera Tommaso Aniello d'Amalfi llamado Masaniello (1620-1647) produce dos efectos: por un lado, desestabiliza el virreinato español y abre paso a la República napolitana, instaurada cinco meses después de su muerte; por otro lado, la apertura de un nuevo frente en el sur debilita la capacidad bélica del ejército español en el otro frente, en el norte. Ambos efectos contribuyen a la firma de la paz de Westfalia el 24 de de octubre de 1648, en el ayuntamiento de Münster, entre las Provincias Unidas de los Países Bajos y España. Con ella, la independencia de las Provincias Unidas es finalmente reconocida, poniendo fin a la Guerra de los Treinta años en Alemania y a la Guerra de los Ochenta Años entre España-donde se la conoce como guerra de Flandes-y los Paises Bajos ${ }^{17}$.

¿Supo Spinoza de Masaniello? ¿Se veía Spinoza como un masaniello holandés? La mayor parte de la vida de Spinoza transcurre en la Holanda del siglo de oro, en un país próspero donde la fiebre religiosa, política, comercial, intelectual y artística imprime su ritmo a la vida de las ciudades celosas de su independencia. En 1672 -el "año catastrófico (rampjaar, en neerlandés)" "18 - las Provincias Unidas son invadidas por una coalición liderada por Francia, pero protegidas parcialmente por unas inundaciones voluntarias: es un fracaso nacional, pero también un fracaso para $\mathrm{J}$ de Witt (1625-1672), Grand Pensionario de Holanda desde 1653, quien es brutalmente asesinado con su hermano Cornelis (1623-1672), el 20 de agosto, por orangistas amotinados. Leibniz cuenta que Spinoza quedó desolado y en secreto quiso poner en el lugar del crimen un pasquín con el título de Ultimi barbarorum (Los últimos de los bárbaros) ${ }^{19}$ : lo que cuenta Leibniz bien pudo ser la reacción de Spinoza ante el cruel asesinato que, de

\footnotetext{
${ }^{17}$ Véase el cuadro de Gerard ter Borch. Juramento de ratificación del Tratado de Münster (1648), Rijksmuseum, Ámsterdam.

${ }^{18}$ Véase a Israel, 1998, pp. 796-806.

${ }^{19}$ La nota que tomó Leibniz durante su visita a Spinoza entre los días 15-17 de 1676 es la siguiente: "He pasado unas horas, después de comer, con Spinoza. Me dijo que el día del asesinato de los señores de Witt había estado a punto de salir de noche y colocar en algún sitio, cercano al lugar, un cartel con la inscripción «ultimi barbarorum» (los últimos de los bárbaros). Pero su hospedero le había cerrado la puerta para impedirle salir, ya que se habría expuesto a ser descuartizado", citado en (Domínguez, 2019, p. 108). No se sabe si J. de Witt hacía parte de los amigos de Spinoza; Gebhardt defiende la tesis de la amistad de Spinoza con J. de Witt (Gebhardt, 1977, capítulo IV), "que ha sido uno de los acontecimientos más trascendentales de lo que podría llamarse la época de Pericles de la historia de Holanda" (Gebhardt,1977, pp. 61-62). Excesiva, esta tesis lo lleva a hacer del Tratado teológico-político uno de los tantos opúsculos políticos provenientes del círculo de Witt cuyos autores "tienen
} 
hecho, ponía fin al gobierno republicano, y a lo que J. de Witt y sus colegas llamaban la "verdadera libertad" (Israel, 2018, p. 371). La afinidad entre el supuesto autorretrato que lo representaba bajo los rasgos de Masaniello y esta anécdota tenían, posiblemente, una significación política personal. Dos años antes del horrendo asesinato, en los primeros meses de 1670, se publica anónimamente en Ámsterdam el Tratado teológico-político, que lleva el subtítulo: "Contiene varias disertaciones, en las que se demuestra que la libertad de filosofar no sólo se puede conceder sin perjuicio para la piedad y para la paz del Estado, sino que no se la puede abolir sin suprimir con ella la paz del Estado e incluso la piedad". Esta "doctrina central del tratado" 20 , que culmina en un último capítulo XX cuyo título es: "Se demuestra que en un Estado libre está permitido que cada uno piense lo que quiera y diga lo que piense", indica que Spinoza y J. de Witt estaban en el mismo lado de la profunda división ideológica que caracterizaba a la sociedad holandesa en el siglo XVII. Sinceros republicanos, ambos abogaron -dentro de ciertos límites- por una relativa tolerancia en lo social, cultural, intelectual y religioso ${ }^{21}$. ¿Por qué defender la libertad de conciencia en un país que pasa por ser el más tolerante de Europa? Porque esta tolerancia no es total. La excomulgación de Spinoza -cuyas verdaderas razones, tanto religiosas como políticas, desconocemos-, el 27 de julio de 1657, y la doble excomulgación de Uriel da Costa, en 1618 y en 1623, por la misma comunidad judía hispano-portuguesa amstelodama, son pruebas de ello. Poco antes de su suicidio, en un atardecer sefardita de 1640, Da Costa escribió su Espejo de una vida humana (Exemplar humamae vitae)22: "Aquí tenéis la verdadera historia de mi vida; y el personaje que en este vanísimo teatro de la vida he interpretado a lo largo de mi vanísima y siempre insegura vida ante vosotros lo exhibo" (Da Costa, 1985, p. 61). El libro o, mejor, el testamento, se abre y se cierra con el terror hacia la condenación eterna (25): “¿Cuántos son los que de su salvación desesperan? (55). Da Costa combatió las tradiciones judías y cristianas y, entre ellas, principalmente la inmortalidad del alma, como Spinoza años después, y afirmó que "vivimos bien cuando vivimos de

por única misión fundamentar y justificar la política de de Witt desde un punto de vista teórico" (Gebhardt,1977, p. 65).

${ }^{20}$ Véase a (Spinoza 1986a, p. 60), la nota 1 de A. Domínguez. "La libertad de filosofar y de expresar lo que pensamos" es una de las razones que lo mueven a escribir el Tratado teológico-político, escribe Spinoza en la carta 30 a Oldenburg de septiembre u octubre de 1665 (1986a, 231). Sobre el contexto histórico en el que Spinoza escribe el TTP, véase a (Madanes, 2001, p. 125, nota 4): "Yo creo que se la (scil. esta obra) comprende mejor si se la considera formando parte del debate de su época en torno a la libertad de expresión".

${ }^{21}$ Véase a (Nadler, 2014, pp. 44-49).

${ }^{22}$ Una mejor traducción de "exemplar" sería "retrato". 
acuerdo con la razón" (53), anticipándose a la Ethica, Ordine Geometrico demonstrata y a la comprensión racional de la ética ${ }^{23}$.

Si Spinoza se pintó a sí mismo bajo la apariencia de Masaniello, escribe P. Totaro en un estudio reciente: "Masaniello, Holanda y un autoretrato", primero debemos ver si, por un lado, la historia del joven napolitano podía ser conocida por el filósofo, y si, por otro lado, apreciaba el valor y el propósito de su empresa. [...] La fortuna misma de la historia de Masaniello en los Países Bajos nos proporciona una clave de interpretación para tratar de reconstruir, al menos en parte, el interés de Spinoza por un acontecimiento histórico en el que es posible reconocer algunas de las razones fundamentales de su pensamiento, ético y político (Totaro, 2020, p. 20).

En primer lugar, la revuelta de Nápoles, con una descripción de su represión y el papel de Masaniello, no solamente fueron transmitidos inmediatamente en Europa por el libro de A. Giraffi, Le Rivolutioni di Napoli Descritte dal Signor Alessandro Giraffi. Con pienissimo ragguaglio d'ogni successo, e trattati secreti, e palesi (Las insurrecciones de Nápoles descritas por el Señor Alessandro Giraffi. Con el relalato completo de cada evento, y tratados secretos y públicos), Venetia, per Il Baba, 1647, sino que, a diferencia de otros países más allá de los Alpes, encontró en Holanda "un terreno particularmente favorable" (Totaro, 2020, p. 21) ${ }^{24}$, debido, en gran medida, a la institución de la república, y al profundo cambio que imprimió en la concepción de la política. En segundo lugar, "En el teatro de Ámsterdam [...] el drama acerca del ascenso y la caída de Masianello, Op- en Ondergang van Mas Anjello, of Napelse Beroerte (Ascenso y caída de Mas Anjello, o la revuelta de Nápoles) de Thomas Asselijn, conocido como Plauto de Ámsterdam, fue puesto en escena en 1650." (ibid., 26). Ahora bien, "Spinoza podría haber asistido a esta representación en el teatro de Ámsterdam que frecuentaba" (ibid., 27), una representación en la cual el público era especialmente sensible a los derechos de las personas oprimidas y a las nuevas exigencias de libertad. En tercer lugar, "Spinoza podía encontrar, todo trazado en la rápida disolución de la parábola de

23 "El naturalismo de da Costa, cuyo Dios se manifiesta en la naturaleza y expresa su ley en la naturaleza, anuncia ya a Spinoza sin que sea necesario admitir una influencia" (Gebhardt, 1977, p. 18). Sobre Uriel da Costa, véase a (Albiac, 1987, pp. 185-252), y a (Yovel, 1989, pp. 42-50).

${ }^{24}$ La primera edición neerlandesa del libro de Giraffi fue publicada en Haarlem en 1650 (ibid., 23). "En el siglo XVII se publicaron 10 ediciones del libro de Giraffi en los Países Bajos, 6 en Amsterdam, 3 en Leiden y 1 en La Haya" (ibid., 21, nota 4), además de varios libros, en vida de Spinoza, acerca de Masaniello y de su fama. 
Masaniello, el paradigma del ascenso político y de la caída brutal que había marcado la trágica historia de los hermanos de Witt, primero aclamados y después linchados en la plaza pública por la misma multitud que los había proclamado como sus representantes y soberanos" (ibid., 32).

El que Spinoza pudo haber asistido a la representación de la obra de Asselijn nos parece bastante creíble. Es conocido el escolio de la Ética en el que Spinoza valora positivamente el teatro:

Así, pues, usar de las cosas y deleitarse con ellas cuanto sea posible (no, por supuesto, hasta la náusea, que eso no es deleitarse), es propio del sabio (viri est sapientis). Es, digo, del varón sabio reponerse y restablecerse con alimentos y bebidas moderadas y suaves, así como con los olores, la amenidad de las plantas verdeantes, los adornos, la música, los juegos gimnásticos, los actos teatrales (theatris) y otras cosas similares, de las que cada uno puede usar sin perjuicio de otro (E4P45E2; G. II, 200, 24-30)

Ahora, al evocar el placer que el sabio siente en el teatro, Spinoza no solamente da cuenta del deleite del espectador, es decir, de un sentimiento común a los neerlandeses de la época, sino también, y sobre todo, de su experiencia - estética- personal como actor. Gracias a Omero Proietti (1991, pp. 9-82), podemos, en efecto, considerar como "casi segura su participación en la representación de dos obras de Terencio en 1657-1658" (ibid., 9) ${ }^{25}$.

El retrato de Spinoza como Masaniello halla eco en Gilles Deleuze: "Negri ha sido, sin duda, el primero que ha conferido su pleno sentido filosófico a la anécdota según la cual Spinoza se había dibujado a sí mismo vestido de Masaniello, el revolucionario napolitano (cf. Lo que Nietzsche dice sobre la importancia de las "anécdotas" propias del "pensamiento en la vida de un pensador")" (Deleuze 1982, 11).

25 "Entre los textos clásicos citados por Spinoza, es notable encontrar con las comedias de Térence El Eunuco y La Andriana. Y en El Eunuco, son sobre todo los textos dichos por o al esclavo Parmeno, los que se citan. ¿Podría ser que Van den Enden le hubiera confiado este importante papel a Spinoza durante la representación de la obra por sus alumnos en el teatro de Ámsterdam, en mayo de 1658?" (Belinfante, Kingma \& Offenberg, 1977, p. 43). Véase a (Rovere, 2020, p. 82), y a (Proietti, 1991), en especial 42-82: "Van den Enden y Spinoza: 1656-1658”. Es posible que Spinoza le esté rindiendo un homenaje a la escuela "latina" de Van den Enden, y de paso critique las escuelas públicas muy controladas por el calvinismo ortodoxo, en el siguiente pasaje del Tratado político: "Las Academias que se fundan con los gastos del Estado, se crean no tanto para cultivar los talentos cuanto para reprimirlos. Por el contrario, en un Estado libre, las ciencias y las artes se cultivan mejor, si se permite a todo el que lo pide enseñar públicamente, pero asumiendo él los gastos y el peligro de su reputación" (VIII, §49; Spinoza, 1986b, pp. 198-199). 
Nietzsche dispone de un método de su invención: no hay que contentarse ni con la biografía ni con la bibliografía, hay que alcanzar un punto secreto en el que es la misma cosa una anécdota de la vida y un aforismo del pensamiento. Es como el sentido que, en una cara se atribuye a estados de vida y, en la otra, insiste en las proposiciones del pensamiento. Hay ahí dimensiones, horas, lugares, zonas glaciares o tórridas, nunca moderadas, toda la geografía exótica que caracteriza un modo de pensar, y también un estilo de vida. Quizá Diógenes Laercio, en sus mejores páginas tuvo un presentimiento de este método: encontrar Aforismos vitales que fueran también Anécdotas del pensamiento: la gesta de los filósofos (Deleuze, 1989, pp. 139-140).

Símbolo de la lucha entre ricos y pobres, entre la nobleza y la burguesía, por un lado, y el pueblo, por otro lado, la imagen de Spinoza vestido con la ropa del joven pescador napolitano emula la interpretación de Negri según la cual la ontología spinociana es política. Símbolo del anhelo de libertad y de felicidad de las clases afectadas, los trabajadores y los marginados, el grabado de Pieter de Jode hace cierta la naturaleza esencialmente social de toda moralidad. Como dice Spinoza al principio del capítulo III del Tratado teológico-político:

La verdadera felicidad y beatitud de cada individuo consiste exclusivamente en la fruición del bien (Vera felicitas, et beatitudo uniuscujusque in sola boni fruitione consistit) y no en la gloria de ser uno solo, con exclusión de los demás, el que goza del mismo. Pues quien se considera más feliz, porque es más feliz y más afortunado que ellos, desconoce la verdadera felicidad y beatitud; ya que la alegría que con ello experimenta, si no es puramente infantil, no se deriva más que de la envidia o del mal corazón (Spinoza 1986a, p. 116; G. III, 44, pp. 14-21).

No podemos sino lamentar la pérdida del cuaderno de los dibujos de Spinoza que, después de su muerte, Van der Spyck decide no vender y que conserva durante casi treinta años. Por supuesto, la observación de que el dibujo se asemeja a la fisionomía de Spinoza es una interpretación de cómo Van der Spyck recuerda a su famoso inquilino, pero la iconografía aplicada al grabado de Pieter de Jode nos permite darle sentido a una anécdota y encontrar en ella la "gesta", como dice Deleuze, de Spinoza.

La simpatía por Spinoza se ve reforzada por su imagen (Simon, 2020). Un rostro delicado enmarcado por una larga melena oscura, una mirada pensativa en sus ojos. Esa imagen cautivadora se transmite a través de los 
tiempos en un retrato de la Biblioteca Herzog August de Wolfenbüttel, en Alemania.

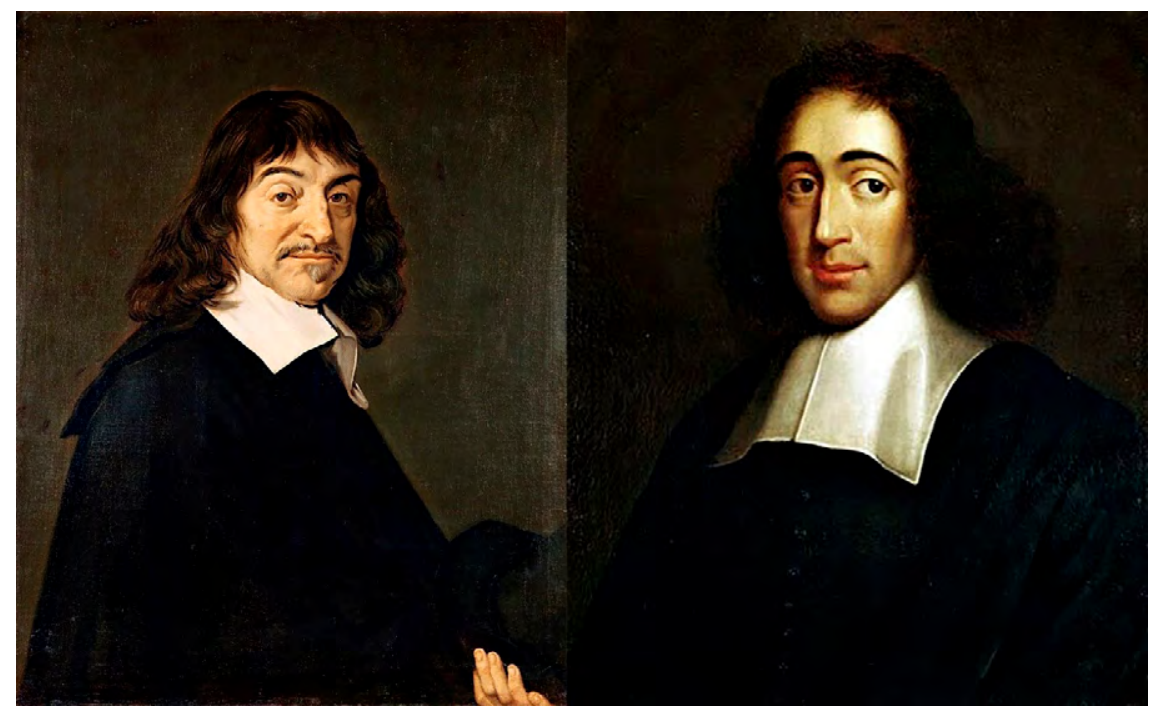

A la izquierda: F. Hals, René Descartes, ca. 1649. Louvre, Paris, Francia. Wikimedia Commons. Dominio público.

A la derecha: Autor desconocido, Baruch Spinoza. ca. 1665. Herzog August Bibliothek, Wolfenbüttel, Alemania. Wikimedia Commons. Dominio público.

Generalmente considerado como un retrato hecho en vida, esta imagen icónica está en el corazón de la iconografía de Spinoza. Con todo, paradójicamente, nos hace pensar inmediatamente en el retrato de Descartes atribuido durante mucho tiempo a Frans Hals (1582-1666), pero que está catalogado ahora como una "copie ancienne d'un original perdu (una copia antigua de un original perdido)", como un "d'après Hals (según Hals), o "una copia de Hals"26. Ambos cuadros comparten la misma factura de un ejercicio académico perfectamente realizado, un fondo oscuro donde se destaca el rostro iluminado, la cabeza descubierta y una vestimenta sobria; ambos cuadros comparten, también, una visión bastante idealizada, que los

${ }^{26}$ Véase nuestro estudio "Una lectura iconográfica de Descartes", que será publicado en el número 182 de Ideas y valores, correspondiente al mes de mayo del 2023. 
asemeja más a una caricatura de lo que deberían ser dos filósofos que forjaron la Modernidad, que a unos hombres vivos, de carne y hueso ${ }^{27}$.

Hendryck van der Spyck, de nuevo, juega un papel fundamental en la historia de las Opera Posthuma ${ }^{28}$. Es probable, en efecto, que, antes del segundo inventario de la sucesión de Spinoza, encontrara sus manuscritos en un pupitre que mandó inmediatamente a Ámsterdam donde los amigos de Spinoza se apresuraron a preparar simultáneamente una edición en latín y una traducción en neerlandés.

B. D. S.

\section{O P E R A \\ P O S T U M A,}

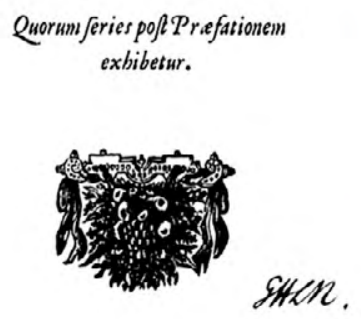

CI O I O C L X X Y I I.

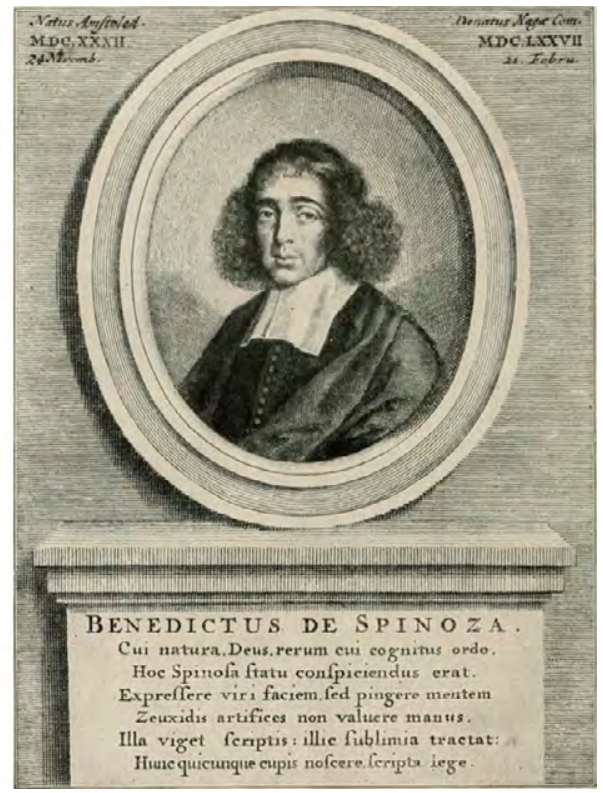

103

A la izquierda, frontispicio de las Opera posthuma, Ámsterdam, J. Rieuwertsz, 1677.

A la derecha, Autor desconocido, Retrato de Spinoza. Ca. 1680. Rijksmuseum, Ámsterdam. Wikimedia Commons. Dominio público.

La imagen de Spinoza (193 x 144 mms) está en un marco circular sobre un zócalo, con su nombre y un poema en latín ${ }^{29}$. El lugar y la fecha de su

${ }^{27}$ Schliesser (2016b) añade un tercer cuadro -ca. 1669-1670- con las mismas características, y casi las mismas dimensiones, el retrato de Hobbes por John Michael Wright (1617-1694), que se encuentra en la National Portrait Gallery, en Londres.

${ }^{28}$ Las Opera posthuma contienen la Ética, el Tratado político, el Tratado de la reforma del entendimiento, las cartas y la Gramática hebráica (Spinoza, 1972).

${ }^{29}$ No se sabe quién es el autor del poema: podrían ser Lodowijk Meijer (1629-1681) o Johannes Bouwmeester (1630-1680), ambos amigos cercanos de Spinoza. 
nacimiento están en la parte superior izquierda: "Natus Amsteled. MDC. XXXII. 24 Novemb. (Nacido en Ámsterdam el 24 de novembre de 1632)"; el lugar y la fecha de su muerte en la parte superior derecha: "Denatus Hagae Com. MDC.LXXVII. 21 February (Muerto en La Haya el 21 de febrero de 1677)". La traducción del poema en latín es la siguiente:

A quien la naturaleza, Dios y el orden de las cosas le fueron conocidos.

Aquí Spinoza podía ser contemplado.

Se representó su rostro, pero pintar su mente.

Ni siquiera lo pudieron las manos hábiles de Zeuxis.

Su mente se engrandece en sus escritos: ahí trata cosas sublimes.

Quienquiera que desee conocerlo, lea sus escritos.

Este grabado en cobre, realizado hacia 1680, probablemente a petición de algunos amigos, y al que se conoce generalmente como "El retrato de las Opera", es llamado así porque fue ejecutado con el fin de incluirlo en varias copias de las Opera Posthuma y de los Nagelate Schriften, ambas ediciones publicadas en 1677. Según Ekkart, "Probablemente se basa en un retrato, que ya no existe, hecho durante la vida del personaje. Se puede considerar como el retrato más fiable de Spinoza, pero no podemos decir con qué fidelidad se han representado sus rasgos, a falta de otros datos" (Ekkart, 1999, p. 13) ${ }^{30}$.

Por falta de argumentos objetivos que permitan identificar a Spinoza entre tantos retratos, tal vez podamos, finalmente, considerar que el "verdadero" retrato de Spinoza es el frontispicio de las Opera posthuma de 1677.

Esta portada sería de un laconismo deprimente si no expresara todo lo que dio origen a la obra. Producto del anonimato (effacement) y de la colegialidad, el pensamiento allí expresado se niega a ser considerado de manera personal. No desea reflejar la sensibilidad de un individuo; tampoco se ve a sí mismo como un cuerpo de doctrinas; la prudente ausencia de un subtítulo sugiere que no demuestra nada en particular, sino que se ocupa de varias cosas específicas -vea la lista después del prefacio-. Eso es todo. Se podría decir que ni siquiera es una filosofía, es filosofia (c'est de la philosophie). El que más trabajó en el libro no quería ser nombrado, porque no le gustaba ver su nombre tomado como un estandarte o considerado como una enfermedad. En este sentido, esta portada quisiera ser al mismo tiempo la lápida del spinozismo y una ventana abierta a la filosofía. Nada más, nada menos.

30 "Es probable que el retrato de Wolfenbüttel haya servido de modelo para esta estampa" (Belinfante, Kingma \& Offenberg, 1977, p. 13, fig. 4). 
Spinoza está muerto. Depende de los lectores convertirse en filósofos (Rovere, 2019, p. 531) $)^{31}$.

\section{Referencias bibliográficas}

Albiac, G. (1987). La sinagoga vacía. Un estudio de las fuentes marranas del espinocismo. Ediciones Hiperión.

Belinfante, J. C., E., Kingma, \& J., Offenberg, A. K. (1977). Catalogue. Spinoza. Troisième centenaire de la mort du philosophe. Institut Néerlandais.

Berger, J. (2011). Bento's Sketchbook. Pantheon Books.

Coffier, J.-C. (1916). Rembrandt et Spinoza. Revue des Deux Mondes, Tomo 31. Exportado de Wikisouce el 2 de febrero de 2021.

Da Costa, U. (1985). Espejo de una vida humana (Exemplar humamae vitae). Ediciones Hiperion.

Deleuze, G. (1982). Préface. En A. Negri, L'anomalie sauvage: puissance et pouvoir chez Spinoza, (pp. 9-12). Presses universitaires de France.

Deleuze, G. (1989). Lógica del sentido. Paidós.

Domínguez, A. (2019). Spinoza. Vida, escritos y sistema de filosofia moral. Escolar y Mayo Editores.

Ekkart, R.E.O. (1999). Spinoza in beeld. Het onbekende gezicht. /Spinoza in Portrait. The unknown face. Vereniging het Spinozahuis.

Gebhardt, C. (1929). Rembrandt y Spinoza. Revista de Occidente, XXIII(69), 307340.

Gebhardt, C. (1977). Spinoza. Losada.

Gombrich, E. \& Eribon, D. (1993). Lo que nos dice la imagen. Conversaciones sobre el arte y la ciencia (1991). Norma.

Israel. J. I. (1998). The Dutch Republic. Its Rise, Greatness, and Fall 1477-1806. Clarendon Press.

Israel. J. I. (2018). Radical thought. En H. J. Helmers \& G. H. Janssen (Eds.), The Cambridge Companion to the Dutch golden Age (pp. 370-389). Cambridge University Press.

Landsberger, F. (1962). Rembrandt, the Jews and the Bible (1946). The jewish publication society of America.

${ }^{31}$ "Tanto en la portada como en otros lugares el nombre de nuestro escritor, escribe Jarig Jelles en el Prefacio a las Opera Posthuma, sólo es impreso con las iniciales por la sencilla razón de que, poco antes de morir, él mismo expresó el deseo de que no se pusiera su nombre a la Ética, que se disponía a imprimir" (Spinoza, 1995, p. 48). Pero, como bien lo aclara D. Tatián, "no se trata de modestia ni de humildad, sino de necesidad filosófica estricta contenida en una vida en la inmanencia"; "Una vida sin museo, una vida -desobrada-, a condición de que el prefijo negativo afecte al sustantivo, no al verbo" (Tatián, 2020, p. 304). 
Madanes, L. (2001). El árbitro arbitrario. Hobbes, Spinoza y la libertad de expresión. Eudeba.

Montoya, P. (2019). La sed del ojo. Random House.

Nadler, S. (1999). Spinoza: a Life. Cambridge University Press.

Nadler, S. (2003). Rembrandt's Jews. University of Chicago Press.

Nadler, S. (2014). A Book Forged in Hell. Spinoza's Scandalous Treatise and the Birth of the Secular Age. Princeton University Press.

Negri, T. (1982). L'anomalie sauvage: puissance et pouvoir chez Spinoza. Presses universitaires de France.

Panofsky, E. (1955). Meaning in the visual Arts. Anchor Books.

Panofsky, E. (1972). Studies in Iconology. Humanistic Themes in the Art of the Renaissance (1939). Icon Editions.

Proietti, O. (1991). Le «Philedonius» de Franciscus van den Enden et la formation rhétorico-littéraire de Spinoza (1656-1658). En Cahiers Spinoza, Tome 6, (pp. 9-82). Éditions Réplique.

Rovere, M. (2019). Le clan Spinoza. Flammarion.

Rovere, M. (2020). Spinoza au théâtre. En P. F. Moreau \& L. Vinciguerra (Eds.), Spinoza et les arts, (pp. 76-89). L'Harmattan.

Schliesser, E. (2016a, Marzo 22). It may look like Spinoza, but it's (probably) not. Digressions \& Impressions. https://digressionsnimpressions.typepad.com/ digressionsimpressions/2016/03/it-may-look-like-spinoza-buts-its-probablynot.html

Schliesser, E. (2016b, Marzo 23). Is it really Spinoza? (Part II). Digressions \& Impressions. https://digressionsnimpressions.typepad.com/ digressionsimpressions/2016/03/is-it-really-spinoza-part-ii.html

Simon, T. (2020, Julio 29). In search of the original Spinoza. The Jerusalem Post. .https://www.jpost.com/jerusalem-report/in-search-of-the-originalspinoza-635965

Spinoza, B. (1972). Opera. Im Auftrag der Heidelberger Akademie der Wissenschaften herausgegeben von Carl Gebhardt (1925), 4 volúmenes. Carl Winters Universitätsbuchhandlung.

Spinoza, B. (1986a). Tratado teológico-político. A. Domínguez (Trad.). Alianza editorial.

Spinoza, B. (1986b). Tratado político. A. Domínguez (Trad.). Alianza editorial.

Spinoza, B. (1988). Correspondencia. A. Domínguez (Trad.). Alianza editorial.

Spinoza, B. (1990). Tratado breve. A. Domínguez (Trad.). Alianza editorial.

Spinoza, B. (1995). Biografias de Spinoza. A. Domínguez (Trad.). Alianza Editorial.

Spinoza, B. (2005). Ética demostrada según el orden geométrico. A. Domínguez (Trad.). z. Editorial Trotta.

Spinoza, B. (2007). Baruc Spinoza. Tratado de la Reforma del Entendimiento y otros escritos (Estudio preliminar, traducción y notas de Lelio Fernández y Jean-Paul Margot). Tecnos, XLIV-88 páginas.

Van Straten, R. (1986). Panofsky and INCONCLASS. Artibus et Historiae, 7(13), 165-181. https://doi.org/10.2307/1483254 
Van Straten, R. (2000). An Introduction to Iconography (1985). Taylor \& Francis. Tatián, D. (2020). Rutinas de la experiencia común. El artista spinoziano como productor. Alpha, (50), 298-307. http://dx.doi.org/10.32735/s07182201202000050795

Totaro, P. (2020). Masaniello, La Hollande et un autoportrait de Spinoza? En P. F. Moreau \& L. Vinciguerra (Eds.), Spinoza et les arts (pp. 19-34). L'Harmattan. Wecker, M. (2016). Is This a Portrait of One of the World's Most Influential Philosophers? Smithsonian Magazine. https://www.smithsonianmag.com/artsculture/portrait-one-worlds-most-influential-philosophers-180960164/

Yovel, Y. (1989). Spinoza and Other Heretics. Vol. I. The Marrano of Reason. Princeton University Press. 
